Working Paper

Business Economic Series

WP. 17-03. July, $10^{\text {th }}, 2017$

ISSN 1989-8843
Instituto para el Desarrollo Empresarial

Universidad Carlos III de Madrid

C/ Madrid, 126

28903 Getafe Madrid (Spain)

FAX +34916249607

\title{
Interest Rate Future Quality Options and Negative Interest Rates
}

\author{
Alejandro Balbás ${ }^{1}$ \\ Departamento de Economía de la Empresa \\ Universidad Carlos III de Madrid
}

Ricardo Laborda ${ }^{2}$

Centro Universitario de Defensa

Academia Militar General

\footnotetext{
${ }^{1}$ C/ Madrid, 126. 28903 Getafe (Madrid, Spain).

${ }^{2}$ Ctra. Huesca s/n. 50090. Zaragoza (Spain).
} 


\title{
Interest Rate Future Quality Options and Negative Interest Rates
}

\author{
Alejandro Balbás ${ }^{a}$ and Ricardo Laborda ${ }^{b * 3}$, \\ aDepartment of Business Administration, University Carlos III of Madrid, CL Madrid, 126. \\ 28903 Getafe, Madrid, Spain. alejandro.balbas@uc3m.es \\ ${ }^{b}$ Centro Universitario de la Defensa. Academia General Militar. Ctra. Huesca s/n. 50090. \\ Zaragoza, Spain. rlaborda@unizar.es
}

\begin{abstract}
This paper verifies the existence of diversification gains from considering the "quality option asset strategy", which adds the portfolio replicating the interest rate future quality option, as proposed by Balbás and Reichardt (2010), and a portfolio comprised of stock and bonds. The empirical results show that the gains are statistically and economically significant, especially in the negative one-month Euribor rate period. The out-of-sample optimal tangency portfolio, which includes "quality option replicas", delivers an increase in the Sharpe ratio of around 40\%, as well as a positive return-loss offsetting the costs of higher turnover. The main source of the diversification gains emanates from the very low correlation between quality options and stocks. Furthermore, the (at least theoretical) existence of sequential arbitrage under negative rates magnifies the low correlation effect.
\end{abstract}

\footnotetext{
$3 *$ Corresponding author: Phone : +34976739844. Email address : rlaborda@unizar.es. Financial support from Gobierno de Aragón and FONDO EUROPEO DE DESARROLLO REGIONAL (CREVALOR) is gratefully acknowledged.
} 
Keywords: Interest rate future quality option, Asset Allocation, Mean-variance frontier, Negative interest rates.

\section{Introduction}

Markowitz (1952) articulated the main foundations of asset allocation in a one-period investor's asset allocation problem. An investor who is only concerned with the mean and variance of the asset return distribution invests optimally by holding a portfolio on the mean-variance frontier that benefits from the effect of diversification across risky assets. Therefore, the investor should, in a first step, find the tangency portfolio that maximizes the Sharpe ratio and in a second step allocate her/his wealth between the risk-free asset and the tangency portfolio depending on her/his attitude towards risk.

Since the seminal work of Markowitz (1952), an extensive theoretical and empirical literature has focused on the search for assets and investment strategies that could expand the mean-variance frontier achieved by traditional assets such as stocks and bonds. To accomplish this goal of expanding the traditional mean-variance frontier, the new assets under consideration should have expected excess returns, volatilities and correlations depending on underlying risk factors distinct from those determining the stock and bond excess returns.

There are many examples of alternative assets or investment strategies available on derivatives markets, commodities markets, equity markets or currency markets, among others, which have been tested to determine whether they expand the traditional mean-variance frontier. Chen et al. (2011) show that volatility-related assets lead to a statistical enlargement of the investment opportunity set for traditional investors, since there is a negative correlation between 
stock returns and volatility changes. Bessler and Wolff (2015) analyse the benefits of including commodities to enhance the performance of traditional portfolios due to their exposure to different risk factors such as the weather, supply conditions or geopolitical risks, as well as their ability to hedge against inflation risk (Erb and Harvey, 2006; Gorton and Rouwenhorst, 2006). They find that the gains vary between different types of commodity and sub-periods in an out-ofsample setting. Jensen et al. (2000) find that the benefits of including commodities futures are especially concentrated in the restrictive monetary environments. Within the universe of equities, Fama and French $(1993,1996)$ show that the empirical power of the standard capital asset pricing model (CAPM) in explaining the cross-sectional variation in average equity returns can be greatly improved if the portfolios are sorted by size and book-to-market ratios. Therefore, the investment strategies that go long in small capitalization (high book-to-price) stocks and short in large (low book-to-price stocks) capitalization stocks also have the potential to expand the mean-variance frontier as these strategies depend on specific macroeconomic risk factors (Liew and Vassalou, 2000). Brandt et al. (2009) confirm this conjecture and find that the optimal allocation to US equities overweighs small firms, value firms and past winners and underweighs large firms, growth firms and past losers using a constant relative risk aversion (CRRA) utility function. Chen et al. (2010) find that adding a value-weighted IPO portfolio does lead to a statistically and economically significant enlargement of the investment opportunity set for investors relative to investing solely in a set of benchmark portfolios. Recent empirical evidence also suggests that currency returns depend on specific risk factors (Burnside, 2012), allowing the investor to engage in profitable and alternative currency strategies. Kroencke et al. (2014) find that foreign exchange investment styles, such as the currency carry trade, the foreign exchange (FX) momentum and the FX value, 
effectively provide significant improvements on traditional portfolios of United States (US) and international stocks and bonds in the statistical and economic sense.

In this paper we analyse the diversification opportunities offered adding by the interest rate future contract quality option to a traditional portfolio comprised of stocks, bonds and the riskfree asset. To do this, we follow the approach of Balbás and Reichardt (2010) in order to price the most expensive quality option usually embedded in the interest rate future contracts. ${ }^{4}$ They show that there is a replicating portfolio of the most expensive quality option that involves trading the future contract value itself and one bond among the set of deliverable bonds: the investor can buy (sell) the quality option through short selling (buying) the discount bond with a face value equal to the interest rate future price and buying (short selling) the deliverable bond that maximizes the quality option value.

Interestingly, Balbás and Reichardt (2010) show that investment strategies involving the quality option (termed the "quality option asset" hereinafter) deliver apparent profitability. Such strategies consist of selling the replicating portfolio of the quality option and buying it later on, profiting from the fact that the quality option price seems to follow a decreasing path. Using a larger sample of data and different interest rate future contracts, we analyse whether investors are better off by including the quality option asset from a statistical and economic point of view. We have considered the investment strategies involving the Euro-Schatz Future contract, the Euro-

\footnotetext{
${ }^{4}$ There are several alternatives for pricing the quality option. As discussed in Balbás and Reichardt (2010) the usual way prices the option at any date before the future maturity as the difference between the theoretical future price of the cheapest to deliver bond and the future price reflected by the market (Hedge, 1990; Hemler, 1990; Stickland, 1992; Yu, 1997).
} 
Bobl Future contract and the Euro-Bund Future contract over the period from June 2012 to December 2016 using daily returns.

To calculate the statistical significance of considering quality option assets to expand the mean-variance frontier obtained from traditional assets, we employ a generalized method of moments (GMM) approach to test the mean-variance efficiency (MacKinlay and Richardson, 1991). We carry out these statistical tests considering the entire sample and also two subsamples that are characterized by the presence of a positive (negative) one-month Euribor rate along the first (second) subsample.

We also investigate the impact of the negative interest rate period on the profitability of the quality option asset. ${ }^{5}$ The recent subprime crisis led to different Central Banks, including the European Central Bank, to employ negative interest rate policies (NIRPs) to provide additional monetary policy stimulus to foster growth, stabilize inflation expectations and relieve currency pressures through charging commercial banks for their excess reserves (Arteta et al., 2016). This monetary policy affected the European money market rates, among others, as reflected by the overnight, one-month and three-month money market rates that declined below zero after NIRP announcements and also provoked a downward shift in different European yield curves as government bond yields turned negative, especially for short-term maturities bonds (Arteta et al., 2016). These policies would also have triggered a search for yield behaviour that, stabilizing the investor sentiment, volatilities and higher order moments of equity returns, which had been

\footnotetext{
${ }^{5}$ Negative interest rates are an unusual phenomenon. Before the subprime crisis and during the 1930s and early 1940s, US Treasury bonds and notes had negative nominal yields as they approached maturity as these securities offered an exchange privilege or option to the owner, who had the right to buy a new security on a future date (Cechetti, 1988).
} 
significantly affected by the sovereign downgrades re-ratings (Brooks et al., 2015). Therefore, the monetary policy that could have led to low interest rates, decreasing volatilities and favourable investor sentiment, could also affect expectations about equity premiums (Ang and Bekaert, 2007; Li and Tsiakas, 2016) and the government bond risk premiums (Laborda and Olmo, 2014; Bansal et al., 2015).

In our asset allocation framework we assume that the investor who is selling the quality option through its replicating portfolio is not going to buy the discount bond with a face value equal to the interest rate future price in order to avoid the payment of interest when the interest rates are negative and is only going to sell the deliverable bond. Thus, we assume a rational investor's behaviour as the investor can always hold cash, which has a zero return, rather than an interestbearing security.

The empirical evidence provided by the previous statistical tests is complemented by an outof-sample experiment that tries to determine the economic significance for investors of considering the option quality assets in their optimal portfolios. Thus, we assume that the investor is aware of the parameter uncertainty and the estimation error associated with the sample mean of the excess returns of the analysed strategies (Merton, 1980) in order to compute the efficient frontier. This is likely to be especially relevant in our setting as our dataset considers a relatively short period of time covering the period 2012-2016, which also captures the unusual period of negative money market rates. Therefore, we pay special attention to the out-of-sample composition of the optimal tangency portfolio and its stability in the period characterized by the presence of a negative one-month Euribor rate. To evaluate the economic significance of the diversification benefits associated with the quality option assets, we consider different metrics in 
our out-of-sample experiment: the Sharpe ratio, the portfolio turnover and the return-loss measure (Daskalaki and Skiadopoulos, 2011; DeMiguel et al., 2009).

Our empirical results lead us to conclude that quality option assets constitute an interesting investment opportunity. From a statistical point of view, the addition of quality option assets to the benchmark assets enlarges the mean-variance frontier in the sample and across the subsamples. From an economic point of view, the out-of-sample average optimal weights in the tangency portfolio allocated to the quality option assets reach a value larger than $20 \%$ and are especially tilted towards the Schatz option quality asset. The out-of-sample average optimal weight in the tangency portfolio that considers the quality option assets for the DAX is significantly reduced compared to the traditional portfolio (from $13 \%$ to $6 \%$ ) and to a lesser extent exposure to the bond market (from $87 \%$ to $72 \%$ ). The main reason explaining the value offered to the investor by the quality option assets is that they are almost uncorrelated with the stock market, but also share with it a negative correlation with the bond market. Furthermore, the (at least theoretical) existence of sequential arbitrage under negative rates magnifies the low correlation effect ${ }^{6}$. These arguments, and the good reward-to-variability ratio offered by the Schatz option quality asset, justify the optimal exposure to this quality option asset being much larger than the DAX optimal exposure.

The percentage change of the Sharpe ratio attributable to the addition of the quality option assets is remarkable at around $40 \%$. While the portfolio turnover analysis shows that the portfolio that includes only traditional assets induces slightly less portfolio turnover, the return-loss

\footnotetext{
${ }^{6}$ See Balbás and López (2008), among others, for further details about relationships between the existence of sequential arbitrage and the properties of the yield curve.
} 
measure is positive, confirming the out-of-sample superiority of the portfolios that include the option quality assets after deducting transaction costs.

The rest of the article is structured as follows. Section 2 presents the methodological background needed to construct the investment strategies involving the quality option assets, the test statistics considered to assess whether the quality option assets expand the mean-variance frontier or not and the economic significance measures used in this paper. Section 3 presents the data. Sections 4 and 5 present the empirical results. Section 6 concludes.

\section{Methodology}

This section explores the methodology developed in this paper. Firstly, we present the main results of Balbás and Reichardt (2010) about the valuation of the quality option embedded in the interest rate future contract. They draw on a classical static approach. Secondly, we define an investment strategy that consists of selling the replicating portfolio of the quality option at period $t$ and buying this replicating portfolio of the quality option at period $t+1$ using a daily basis. This investment strategy will constitute our quality option asset and will profit from the decreasing quality option price path suggested by the empirical analysis of Balbás and Reichardt (2010). Thirdly, we investigate the statistical and economic significance of adding the quality option asset to an initial investor opportunity set comprised of traditional assets such as stocks and bonds. We describe the GMM approach to testing mean-variance efficiency, following MacKinlay and Richardson (1991), and define the metrics used to investigate the investor's gain from considering the quality option asset in the investment opportunity set. 


\subsection{Replicating and pricing the interest rate future quality option}

The quality option can be replicated and priced by drawing on the classical static approach of financial economics (Balbás and Reichardt, 2010). Thus, we consider the current date $t_{0}=0$ and a future one denoted by $T$. There are $n$ risky securities $B_{1}, B_{2}, . ., B_{n}$, a riskless asset whose interest rate between 0 and $T$ is represented by $r$, and a future contract $F$ with maturity at $T$ and whose underlying assets are $B_{1}, B_{2}, \ldots, B_{n}$. The quality option will be exercised by the future seller. The (numerical) initial price of $B_{j}$ is denoted by $p_{o, j}, j=1,2, \ldots, n$ and $f$ is the initial future quotation. The (random) final price of $B_{j}$ will be $p_{j}, j=1,2, \ldots, n$, and $f^{*}$ will denote the future price at maturity.

There is a conversion factor $\delta_{j}>0$ that affects $B_{j}, j=1,2, \ldots, n$, so the pay-off received by the future seller at maturity is given by $f-f^{*}+\delta_{i} f^{*}-p_{i}$, if he/she delivers $B_{i}$. To prevent the existence of arbitrage at $T$, the expression $0=\left(\delta_{i} f^{*}-p_{i}\right) \geq\left(\delta_{j} f^{*}-p_{j}\right) \forall j$ must hold, so we obtain

$$
f^{*}=\frac{p_{i}}{\delta_{i}} \leq \frac{p_{j}}{\delta_{j}} \quad \forall j=1,2, \ldots, n
$$

Therefore, the final pay-off of the future seller becomes $f-f^{*}$. Security $B_{i}$ is usually called the cheapest to deliver (CTD) asset.

To price the quality option, Balbás and Reichardt (2010) show that it can be replicated with the available securities by means of a static portfolio. Therefore, the price of the replicating portfolio allows us to price the future contract quality option using a simple arbitrage-linked argument. Thus, let us construct a new strategy replicating the sale of the previous future contract. So, fix $i$ between $j=1,2, \ldots, n$ and consider the theoretical derivative contract $F_{i}$, allowing the seller to deliver 
$1 / \delta_{i}$ units of $B_{i}$ at $T$ for $f$ monetary units. Let $Q_{i}$ be the option permitting the buyer to receive $1 / \delta_{i}$ units of $B_{i}$ at $T$ if he/she delivers $1 / \delta_{j}$ units of the chosen security $B_{j}$, which belongs to the set $\left\{B_{1}\right.$, $\left.B_{2}, \ldots, B_{n}\right\}$. Hence, the buyer has choice among the set $\left\{B_{1}, B_{2}, \ldots, B_{n}\right\}$.

Balbás and Reichardt (2010) give the proofs of the following propositions:

Proposition 1: The sale of $F$ may be replicated by the sale of $F_{i}$ and the purchase of $Q_{i}, i=1,2, \ldots$, $n$.

It is important to highlight that according to the abovementioned statement, the sale of $F$ incorporates $n$ implied quality options $Q_{1}, Q_{2}, \ldots, Q_{n}$. Each option $Q_{j}$ is associated with security $S_{j}$, $j=1,2, \ldots, n$.

Proposition 2: The price of $Q_{j}$ is given by

$q=\frac{p_{0, j}}{\delta_{j}}-\frac{f}{(1+r)^{T}} \quad j=1,2, \ldots \ldots . .$.

Eq. (2) clearly points out that all the implied quality options do not necessarily have the same price. Balbás and Reichardt (2010) consider the most expensive one to introduce "the quality option price" instead of the cheapest one usually considered in the literature. Therefore, we estimate the quality option price as follows:

$q=\max \left(\frac{p_{0, j}}{\delta_{j}}-\frac{f}{(1+r)^{T}}\right) \quad j=1,2, \ldots \ldots . .$.

The option with the highest value is also related to the future contract $F$ in the sense that it can also be replicated by using $F$ (Proposition 1 ). To replicate the purchase of the quality option, 
an investor should borrow $f /(1+r)^{T}$ monetary units and buy $1 / \delta_{j}$ units of $B_{j}$. Conversely, the sale of the quality option is replicated by lending $f /(1+r)^{T}$ monetary units and selling $1 / \delta_{j}$ units of $B_{j}$. Moreover, Eq. (2) shows that the only difference between the cheapest and the most expensive quality options is given by a position in the bonds involved (in proportions given by the conversion factors). Thus, the replicating portfolios are almost identical, and the only difference is given by the bond to be traded. In this regard, if we consider that the quality option is an interesting security in itself, the price of both options should dynamically reflect quite parallel behaviours. A fundamental advantage of considering the expensive option is that it will not be affected by the lack of the underlying bond if manipulators appear (Järvinen and Käppi, 2004; Merrick et al., 2005).

\subsection{Investment strategies involving the interest rate future quality option}

In this section we define the investment strategy linked to the replica of the quality option that we consider as an asset that could be interesting to many traders in order to improve the the risk/return efficient frontier. Balbás and Reichardt (2010) suggest that a strategy that could be profitable, based on their empirical evidence of a decreasing quality option price path, is to sell the quality option (or the replica) so as to buy a few days before maturity. Their results, using perfectly synchronized data for the ten years German bond, show that the strategy is very beneficial to the investor and the profits are especially higher if one sells the replica in a period distant from the maturity date and keeps the option in the portfolio. In doing so, the investor seems to profit from the decreasing quality option price path. 
Balbás and Reichardt (2010) also remark that this investment strategy implies positive effects on the viability of the future contract. The sale of the quality option (or the replica) implies the purchase of the future contract, providing hedgers with liquidity. Similarly, a few days before maturity, the sale of the future will again assist hedgers as they will buy the future if they cannot deal with the CTD bond due to manipulations. On the other hand, replicating the most expensive quality option prevents the use of the CTD bond, so traders using the quality option as an asset will not be affected by manipulators.

We analyse Balbás and Reichardt's (2010) investment strategy using a classical approach and an enlarged dataset. We consider an investor who sells the option (or the replica) at $t$ and buys the option (or the replica) at $t+1$. The cash flow, $C F$, of this strategy at $t+1$ is:

$C F=\left(\frac{p_{t, j}}{\delta_{j}}-\frac{f_{t}}{(1+r)^{T}}\right)-\left(\frac{p_{t+1, j}}{\delta_{j}}-\frac{f_{t+1}}{(1+r)^{T-1}}\right)$.

If $B_{j}$ pays coupon $c_{j}$ at $t_{t o}\left(t \leq t_{t 0} \leq T\right)$ then Eq. (4) becomes:

$C F=\left(\frac{p_{t, j}}{\delta_{j}}-\frac{f_{t}}{(1+r)^{T}}-\frac{c_{t, j}}{(1+r)^{t_{t 0}}}\right)-\left(\frac{p_{t+1, j}}{\delta_{j}}-\frac{f_{t+1}}{(1+r)^{T-1}}\right)$

and if $S_{j}$ pays coupon $c_{j}$ at $t_{t 1}\left(t+1 \leq t_{t 1} \leq T\right)$, Eq. (5) becomes:

$C F=\left(\frac{p_{t, j}}{\delta_{j}}-\frac{f_{t}}{(1+r)^{T}}\right)-\left(\frac{p_{t+1, j}}{\delta_{j}}-\frac{f_{t+1}}{(1+r)^{T-1}}-\frac{c_{t, j}}{(1+r)^{t_{t 1}}}\right)$.

We also investigate the impact of the negative interest rate period on the profitability of the investment strategy that replicates the quality option. To do so, we assume that the investor who 
is selling the quality option through its replica is not going to lend $f /(1+r)^{T}$ monetary units, as stated above, in order to avoid the payment of interest when the interest rates are negative. Consequently, the investor will only sell $1 / \delta_{j}$ units of $B_{j}$.

We define the daily return of the strategy as the logarithm of $C F$ and therefore we are able to create a daily return time series associated with our strategy for each interest rate future contract during the period September 2012 - December 2016. These daily returns reflect the behaviour of the quality option asset.

\subsection{Measuring quality option diversification benefits. GMM mean-variance tests and out-of-} sample economic significance

We evaluate the statistical significance of the diversification possibilities of considering quality option assets as well as the out-of-sample economic significance of these possibilities.

In order to calculate the statistical significance we employ a GMM approach to test meanvariance efficiency (MacKinlay and Richardson, 1991), which is especially suitable if the assumption of multivariate normality of excess asset returns does not necessarily apply.

Let $R_{1}$ be the $T_{M V \times} K$ matrix of realized excess returns on the $K$ benchmark assets over $T_{M V}$ periods. Similarly, let $R_{2}$ be the $T \times N$ matrix of realized excess returns on the $N$ test assets. Consider the following linear regression of the test asset excess returns on the benchmark asset excess returns: 
$R_{2 t}=\alpha+\beta R_{1 t}+\varepsilon_{t}$

where $\alpha$ is a $N \times 1$ vector of constant terms, $\beta$ is a $K \times N$ matrix of loadings of the test assets on the benchmark assets and $\varepsilon_{t}$ is a vector of disturbance terms in period $t$. Thus: $\sum=\operatorname{var}\left(\varepsilon_{t}\right)$.

Huberman and Kandel (1987) show that testing for spanning of the test assets by the benchmark assets involves checking the following parameter restrictions:

$\alpha=0 \quad \beta 1_{K}=1_{N}$.

Since we use GMM to estimate the model, we do not impose strong assumptions about the disturbance term in Eq. (7) and we only need data that are stationary and ergodic and the existence of the fourth moment of excess asset returns (MacKinlay and Richardson, 1991). The residual distribution does not need to be independent and identically distributed (i.i.d.).

The GMM begins with the definition of the disturbance term:

$\varepsilon_{t}=R_{2 t}-\alpha-\beta R_{1 t}$

We define the $(K+1) N$ vectors $f_{t}(\alpha, \beta)$ and $g_{T_{M W}}(\alpha, \beta)$ as follows:

$$
\begin{aligned}
& f_{t}(\alpha, \beta)=\left[\begin{array}{l}
\varepsilon_{i t}\left(\alpha_{i}, \beta_{i}\right) \\
\varepsilon_{i t}\left(\alpha_{i}, \beta_{i}\right) R_{t}^{1}
\end{array}\right] \quad i=1, \ldots . N \\
& g_{T_{M W}}(\alpha, \beta)=\frac{1}{T_{M W}} \sum_{t=1}^{T_{M W}} f_{t}\left(\alpha_{i}, \beta_{i}\right)
\end{aligned}
$$


We employ the moment condition $E\left[f_{t}(\alpha, \beta)\right]=0$ for estimation and testing using the GMM approach. To conduct the GMM mean-variance test, we adopt a restricted approach and replace the restriction $\alpha=0, \beta 1_{K}=1_{N}$ into Eq. (10), estimating the restricted system and then testing the over-identifying constraints (MacKinlay and Richardson, 1991). The number of orthogonality conditions is $(K+1) N$ larger than the number of estimated parameters, $(K-1) N$. Hence, the system is over-identified and we use the Hansen (1982) test of over-identifying restrictions to validate if the sample moments represented by Eq. (11) are as close to zero as would be expected if the corresponding population moments were truly zero. As always, a $p$-value close to zero implies that the $N$ test assets expand the investor's opportunity and the investor would obtain diversification benefits from considering the new $N$ test assets; otherwise the mean-variance frontier of the $K$ benchmark assets coincides with that of the augmented assets and the investor would not gain benefits from considering the additional $N$ new assets. We carry out the test of mean-variance efficiency using all the sample data and also considering two sub-periods that are mainly characterized by the presence of a positive (negative) one-month Euribor rate along the first (second) sub-period.

To evaluate the economic significance of the diversification benefits associated with the quality option assets, we consider different metrics in an out-of-sample experiment (see, e.g. Daskalaki and Skiadopoulos, 2011; DeMiguel et al., 2009). 
1) We take the annualized Sharpe ratio ${ }^{7}(S R)$, defined as the fraction of the sample mean of out-of-sample excess returns $(\mu)$ divided by their sample standard deviation $(\sigma)$, for the meanvariance tangency portfolio based on the $K$ benchmark assets or based on the $K$ benchmark assets and the $N$ quality option assets,

$S R=\mu / \sigma$

2) We consider the portfolio turnover (PT) metric, defined as the average absolute change of the weights over the $T-L$ rebalancing points in time across the $K$ benchmark assets or based on the $K$ benchmark assets and the $N$ quality option assets,

$P T=\frac{1}{T-L} \sum_{t=1}^{T-L} \sum_{j=1}^{Q}\left(\left|w_{j, t+1}-w_{j, t}\right|\right) \quad Q=N$ or $N+K$,

where $w_{j, t+1}$ and $w_{j, t}$ are the weights of asset $j$ at time $t$ and $t+1$ in the mean-variance tangency portfolio.

3) We consider the return loss that allows the investor to incorporate the effects of transaction costs. Let $r_{p, t+1}$ be the realized portfolio return at $t+1$. The evolution of the net of transaction costs wealth, $W_{N T C, t+1}$, assuming a proportional transaction cost, $C_{p}$, is given by

$$
W_{N T C, t+1}=W_{N T C, t}\left(1+r_{p, t+1}\right)\left[1-C_{p}\right] \sum_{j=1}^{Q}\left(w_{j, t+1}-w_{j, t} \mid\right) \quad Q=N \text { or } N+K,
$$

\footnotetext{
${ }^{7}$ It is well known that the Sharpe ratio, or price of risk, is the slope of the line from the risk-free rate to any portfolio in the mean-standard deviation plane (Sharpe, 1994) and it is related to the volatility of the stochastic discount factor that prices assets. A difference between these two Sharpe ratios implies that investors can increase their risk-return trade-off by considering the $N$ additional assets.
} 
The return net of transaction costs is defined as

$$
R_{N T C, t+1}=\frac{W_{N T C, t+1}}{W_{N T C, t}}-1,
$$

Let $\mu_{\text {qualityoption }}, \mu_{\text {Traditional assets }}$ the daily out-of-sample sample means of the strategy that includes the quality option assets and the restricted opportunity set, respectively, and $\sigma_{\text {quality option }}, \sigma_{\text {Traditional assets }}$, be the corresponding standard deviations. The return-loss measure is given by

return - loss $=\frac{\mu_{\text {qualityoption }}}{\sigma_{\text {qualityoption }}} \sigma_{\text {Traditional assets }}-\mu_{\text {Traditional assets }}$.

Following DeMiguel et al. (2009), we set the proportional transaction cost $C_{p}$ equal to 50 basis points per transaction for all the assets.

\section{The dataset}

This section starts by describing the data used in the empirical analysis and then presents and discusses the empirical results obtained from the pricing of the quality option and the implementation of the investment strategy involving the quality option. We conduct the GMM mean-variance spanning test and analyse the out-of-sample economic significance of including the quality option asset in the investor's opportunity set. The last empirical analysis is divided into an in-sample and an out-of-sample period. 


\subsection{Data description}

We have computed the quality option price according to Eq. (3) using the Euro-Schatz Future contract, the Euro-Bobl Future contract and the Euro-Bund Future contract. Table 1 shows their main contract specifications. The underlying asset is a notional bond issued by the German government whose annual coupon equals $6 \%$. The contract nominal value is EUR 100,000 and prices represent a percentage of the par value with two decimal digits. There are four available maturities, March, June, September and December, although the shortest one reflects the greatest activity. The future contract can be traded until two days before its maturity at 12:30 pm. The delivery must take place on the 10th day of the delivery month and the deliverable assets are bonds issued by the German government with different maturities depending on the interest rate future contract. Each interest rate future contract presents a different number of quality options as there are different bonds involved. The conversion factor is the bond price per unit of nominal value at the future expiration and under a flat term structure of interest rates equal to the notional bond coupon.

\section{[Insert Table 1 about here]}

Our sample covers the period from June 2012 to December 2016. We collect closing daily data from Datastream on the deliverable bond prices for each interest rate future contract with the shortest maturity, the corresponding future prices and the one-month and three-month Euribor rates. We also collect closing daily prices from Datastream on the DAX and a German government 
bond index provided by JPM to analyse the diversification benefits of the quality option asset. The total number of observations, $T_{M V}$, equals 1098.

\subsection{The quality option price}

First, we have computed the closing price of the quality options every day according to Eq. (3) for each interest rate future contract. Table 2 provides the summary statistics of the quality option considering the entire sample and the two subsamples that are mainly characterized by the presence of a positive (negative) one-month Euribor rate along the first (second) subsample. The negative one-month Euribor rate sub-period starts from 26 February onwards and the corresponding number of observations is 443 , which accounts for around $40 \%$ of the total observations.

Table 2 shows that across the different interest rate future contracts, the average of the quality option price is clearly significant. Within the different interest rate futures contracts we observe that the average of the quality option price increases with the maturity of the deliverable bonds. Considering the entire sample, we find that the average quality option price is around $2.5 \%$ of the future nominal value using the Euro-Schatz Future contract, around $3.5 \%$ of the future nominal value using the Euro-Bobl Future contract and around 5\% using the Euro-Bund Future contract. We also observe that the average quality option price is higher in the negative onemonth Euribor rate sub-period than in the positive one-month Euribor rate sub-period.

[Insert Table 2 about here] 


\section{Mean-variance frontier expansion using the quality option assets}

Table 3 reports the main descriptive statistics of the quality option asset returns considered in this paper. Interestingly, all the quality option assets except the Schatz one have volatility, average return and kurtosis larger than the DAX and the German government bond index considering the whole sample. The results are especially explained by the behaviour of the quality option asset returns during the negative one-month Euribor rate sub-period. During the positive one-month Euribor rate sub-period, the quality option asset average returns are only higher than the German government bond index returns.

Also interestingly, the quality option asset returns also have a negative correlation with the German bond index and are almost uncorrelated with the DAX. Consequently, diversification benefits may emerge as a consequence of these correlation patterns between the quality option assets and more traditional assets.

[Insert Table 3 about here]

Table 4 reports the GMM mean-variance spanning results considering the data for the whole sample and across the subsamples. We compute the test for each quality option asset separately ( $N=1$ and $K=2$ ). Hence, we answer the question of which quality option assets expand the meanvariance frontier based on the DAX, the German government bond index and the one-month Euribor rate considered as the risk-free rate. Finally, we conduct the analysis considering all the quality option assets ( $N=3$ and $K=2)$. 
Individually, all the quality option assets added to the benchmark assets for the period June 2012 to December 2016 result in an enlargement of the mean-variance frontier considered ( $p$ value equal to 0) for the whole sample and across the subsamples. The results remain unchanged when we consider all the quality option assets added at once to the benchmark assets.

[Insert Table 4 about here]

Table 5 shows the optimal portfolio weights in the tangency portfolio for an investor who invests only in the traditional risky assets or also considers the quality option assets in the investment opportunity set. We do not impose short-sale restrictions on the quality option assets given the optional nature of the investment strategies considered. We do impose short-sale restrictions on the stock and bond assets.

The table indicates that the weight for the Schatz quality option asset is positive, reaching a value close to $32 \%$, which is much larger than the value allocated to the DAX (19\%). The optimal weight allocated to the Bund quality option asset is also positive (1\%) and the weight allocated to the Bobl quality option asset is negative $(-3 \%)$. The table also reports a decrease in the optimal weight allocated to the DAX and the German government bond index in the tangency portfolio when adding the quality option assets to the investment opportunity set that is only composed of traditional assets (from $19 \%$ to $6 \%$ and from $81 \%$ to $64 \%$ respectively). Hence, the total optimal weights allocated to the quality option assets reach a positive value of around $30 \%$. The nature of these results is preserved across the subsamples but is especially relevant in the negative onemonth Euribor rate sub-period in which the weight allocated to the quality option assets almost reaches $40 \%$ due to the decreasing allocation of wealth to the DAX, which varies from $31 \%$ in the traditional mean-variance tangency portfolio to $2 \%$ in the expanded mean-variance tangency 
portfolio. A sensible reason for this rebalancing towards the quality option assets is that the Schatz quality option asset and the DAX are almost uncorrelated and share almost the same negative correlation with the German government index, but the former has a higher average return and lower volatility than the stock index.

[Insert Table 5 about here]

\section{Out-of-sample economic significance of the quality option assets}

The previous GMM mean-variance tests show that the quality option assets do indeed expand the mean-variance frontier and consequently would allow the investor to attain a better reward-tovariability ratio. These in-sample tests implicitly assume there is perfect knowledge of the expected asset returns and their volatilities and correlations. However, the empirical evidence shows a clear difficulty in delivering consistently superior out-of-sample forecasts of the associated models relative to a simple forecast based on the historical average (Welch and Goyal, 2008). Thus, the investor should be aware of the estimation error, especially in the sample mean (Merton, 1980), in order to compute the efficient frontier and assess adequately the diversification gains of the quality option assets.

Therefore, in this section we check the robustness of the previous empirical findings and evaluate their economic out-of-sample significance. We compare the performance of the expanded investment opportunity set using the quality option assets added to the traditional investment opportunity set comprised of traditional assets using the aforementioned metrics: i) the annualized Sharpe ratio, ii) the portfolio turnover (PT) metric and iii) the return loss. 
Our out-of-sample period coincides with the negative one-month Euribor rate sub-period. Thus, the first optimal tangency portfolio is estimated with data from 12 June 2012 to 25 February 2015 and this model is then re-estimated daily using a "rolling window" of data that each day incorporates the realized asset returns and drops the data for the earliest day. Therefore, the outof-sample period covers around $40 \%$ of the total data and the length of the estimation window around $60 \%$ of the total data.

Table 6 reports the out-of-sample optimal portfolio weights contained in the tangency portfolio statistics. As for the in-sample analysis, the average optimal weights allocated to the quality option assets reach a positive value of around $22 \%$, especially tilted towards the Schatz option quality asset, which leads the investor to halve the allocation to the DAX and reduce significantly exposure to the bond market (from $87 \%$ to $72 \%$ ). It is also worth noting that the optimal Schatz option quality asset volatility is the largest among the different assets. Figure 1 plots the dynamics of the tangency portfolio weights during the out-of-sample period. It is easy to observe the stability of these weights, the outweighing of the German government bond index and the increasing weight allocated to the Schatz option quality asset, which reaches values larger than $25 \%$, coinciding with a decreasing pattern of the DAX optimal weight, which almost reaches the zero lower bound.

[Insert Table 6 about here]

[Insert Figure 1 about here] 
Table 7 shows the economic significance of including the quality option assets in the investor portfolio. ${ }^{8}$ The Sharpe ratio for the tangency portfolio increases from 1.41 to 1.99 due to the addition of the quality option assets. The percentage change in the Sharpe ratio attributable to the addition of the quality option assets is remarkable at around $40 \%$. The annualized mean return for the tangency portfolio increases from $4.3 \%$ to $7.4 \%$. The portfolio turnover analysis shows that the portfolio that includes only the traditional assets induces a slightly lower portfolio turnover compared with the portfolio that also includes the quality option assets. However, the return-loss measure is $1.75 \%$, confirming the out-of-sample superiority of the portfolios that include the option quality assets after deducting transaction costs.

[Insert Table 7 about here]

Figure 2 plots the evolution of the tangency portfolio wealth in the out-of-sample period considering traditional assets versus the investors who also include the quality option assets. During the period 26 February 2015 to 8 December 2016, one euro invested in the tangency portfolio that only includes traditional assets increases to EUR 1.07. In the same period, the tangency portfolio wealth with quality option assets increases to EUR 1.12.

[Insert Figure 2 about here]

\footnotetext{
${ }^{8}$ The results obtained are qualitatively robust to the consideration of different lengths of the estimation window in the rolling procedure used to estimate the out-of-sample optimal tangency portfolio. The results can be provided by the authors upon request.
} 


\section{Conclusion}

This paper verifies the existence of diversification gains from considering the "quality option asset strategy", which adds the portfolio replicating the interest rate future quality option, and a portfolio comprised of stock and bonds.

The GMM mean-variance tests carried out for the whole sample and across the subsamples show that the quality option assets do indeed expand the mean-variance frontier and, consequently, allow the investor to attain a better reward-to-variability ratio. It is remarkable that in the negative one-month Euribor rate sub-period the weight allocated to the quality option assets almost reaches $40 \%$ due to the decreasing allocation of wealth to the DAX in the expanded mean-variance tangency portfolio. The main source of the diversification gains emanates from the very low correlation between quality options and stocks. Furthermore, the (at least theoretical) existence of sequential arbitrage under negative rates magnifies the low correlation effect.

The empirical results show that gains are statistically and economically significant, especially in the negative one-month Euribor rate period. The out-of-sample optimal tangency portfolio, which includes "quality option replicas", delivers an increase in the Sharpe ratio of around $40 \%$, as well as a positive return-loss offsetting the costs of higher turnover. It is also noteworthy that tangency portfolio weights during the out-of-sample period show a sensible stability, but with an increasing weight allocated to the Schatz option quality asset, and a decreasing pattern of the DAX optimal weight, which almost reaches the zero lower bound. 


\section{References}

Ang, A., Bekaert, G. 2007. Stock Return Predictability: Is it There?. Reviev of Financial Studies, 20 (3), 651-707.

Arteta, C. Ayhan, M., Stocker, M., Taskin, T. 2016. Negative interest rates policies: Sources and implications. International Macroeconomics and Finance CEPR Working Paper, DP11433.

Balbás, A., López, S. 2008. Sequential arbitrage measurement and interest rate envelopes. Journal of Optimization Theory and Applications, 138, 3, 361-374.

Balbás, A., Reichardt, S. 2010. On the future contract quality option: A new look. Applied Financial Economics, 20, 1217-1229.

Bansal, N., Connolly, R., Stivers, C. 2015. Equity volatility as a determinant of future term-structure volatility. Journal of Financial Markets, 25, 33-51.

Brandt, M., Santa Clara, P., \& Valkanov, R. (2009). Parametric portfolio policies exploiting the characteristics in the cross section of equity returns. Review of Financial Studies, 22, 3411-3447.

Bessler, W., Wolff, D. 2015. Do commodities add value in multi-asset portfolios? An out-of-sample analysis for different investment strategies. Journal of Banking and Finance, 60, 1-20.

Brooks, R., Faff, R., Treepongkaruna, S., Wu, E. 2015. Do sovereign re-ratings destabilize equity markets during financial crisis?. New evidence from higher return moments. Journal of Business Finance and Accounting, 42 (5), 777-799. 
Burnside, C. 2012. Carry trades and risk. In James, J., Marsh, I.W., Sarno, L. (Eds.), Handbook of Exchange Rates (pp. 283-312). John Wiley \& Sons, Hoboken.

Cechetti, S. 1988. The case of negative nominal interest rates: New estimates of the term structure of interest rates during the Great Depression. Journal of Political Economy, 96 (6), 1111-1141.

Chen, H., Chung, S., Ho, K. 2011. The diversification effects of volatility-related assets. Journal of Banking and Finance, 35, 1179-1189.

Chen, H., Ho, K., Hsiao, Y., Wu, C. 2010. The diversification effects of Initial Public Offerings. Journal of Business Finance and Accounting, 37(1), 171-205.

Daskalaki, C., Skiadopoulos, G. 2011. Should investors include commodities in their portfolios after all? New evidence. Journal of Banking and Finance, 35, 2606-2626.

DeMiguel, V., Garlappi, L., Nogales, F., Uppal, R., 2009. A generalized approach to portfolio optimization: improving performance by constraining portfolio norms. Management Science, 55, 798-812.

Erb, C.B., Harvey, C.R., 2006. The strategic and tactical value of commodity futures. Financial Analysts Journal, 62, 69-97.

Fama, E., French, K. 1993. Common risk factors in the returns on stock and bonds. Journal of Financial Economics, 33, 3-56.

Fama, E., French, K. 1996. Multifactor explanations of asset pricing anomalies. Journal of Finance, 51, $55-84$. 
Gorton, G.B., Rouwenhorst, K.G. 2006. Facts and fantasies about commodity futures. Financial Analysts Journal, 62, 47-68.

Hansen, L. (1982). Large sample properties of generalized method of moments estimators. Econometrica, 50, 1029-1054.

Hedge, S. 1990. An ex post valuation of the quality option implicit in the treasury bond futures contract. Journal of Banking and Finance, 14: 741-60

Hemler, M. 1990. The quality delivery option in treasury bond futures contract. The Journal of Finance, 45: 1565-86.

Huberman, G., Kandel, S. 1987. Mean-variance spanning. Journal of Finance, 42, 873-888.

Järvinen, S., Käppi, J. 2004. Manipulation of the bund futures market. Applied Financial Economics, 14, 799-808.

Jensen, G., Johnson, R., Mercer, J. 2000. Efficient use of commodity futures in diversified portfolios. The Journal of Futures Markets, 20 (5), 489-506.

Kroencke, T., Schindler, F., Schrimpf, A. 2014. International diversification benefits with foreign exchange investment styles. Review of Finance, 18 (5), 1847-1883.

Laborda, R., \& Olmo, J. (2014), Investor sentiment and bond risk premia, Journal of Financial Markets 18, 206-233. 
Li, J., Tsiakas, I. 2016. Equity premium prediction: the role of economic and statistical constraints. Journal of Financial Markets. Accepted for publication. http://dx.doi org/10.1016/j.finmar.2016.09.001

Liew, J., Vassalou, M. 2000. Can book-to-market, size and momentum be risk factors that predict economic growth? Journal of Financial Economics, 57, 221-245.

MacKinlay, A., Richardson, M. 1991. Using generalized method of moments to test mean-variance efficiency. Journal of Finance, 46 (2), 511-527.

Markowitz, H.M. 1952. Mean-variance analysis in portfolio choice and capital markets. Journal of Finance, 7, 77-91.

Merrick, J., Naik, N., Yaday, P. 2005. Strategic trading behavior and price distortion in a manipulated market: Anatomy of a squeeze. Journal of Financial Economics 77, 171-218.

Merton, R.C. 1980. On estimating the expected return on the market: An exploratory investigation. Journal of Financial Economics, 8, 323-361.

Sharpe, W. 1994. The Sharpe ratio. Journal of Portfolio Management, 20, 47-58.

Stickland, C. 1992. The delivery option in bond futures contracts: an empirical analysis of the LIFFE Iong gilt future contract. The Review of Futures Markets, 11: 84-102.

Welch, I., Goyal, A. 2008. A comprehensive look at the empirical performance of equity premium prediction. The Review of Financial Studies, 21(4), 1455-1508.

Yu, SW. 1997. Term structure of interest rates and implicit options: the case of Japanese bond futures. Journal of Business Finance and Accounting, 24: 593-614. 
Table 1

Contract specifications: fixed-income futures

\begin{tabular}{|c|c|c|c|}
\hline & Euro-Schatz Futures & Euro-Bobl Futures & Euro-Bund Futures \\
\hline Contract standard & \multicolumn{3}{|c|}{$\begin{array}{l}\text { Notional short-, medium- or long-term debt securities issued by the Federal } \\
\text { Republic of Germany with a coupon of } 6 \% \text {. }\end{array}$} \\
\hline Remaining term & 1.75 to 2.25 years & 4.5 to 5.5 years & 8.5 to 10.5 years \\
\hline Contract value & EUR 100,000 & EUR 100,000 & EUR 100,000 \\
\hline Delivery day & \multicolumn{3}{|c|}{$\begin{array}{l}\text { The tenth calendar day of the respective quarterly month if this day is an } \\
\text { exchange day; otherwise the exchange day immediately following that day. }\end{array}$} \\
\hline Last trading day & \multicolumn{3}{|c|}{$\begin{array}{l}\text { Two exchange days prior to the delivery day of the relevant maturity month. } \\
\text { Close of trading in the maturing futures on the last trading day is at } 12: 30 \\
\text { CET. }\end{array}$} \\
\hline Minimum price change & $\begin{array}{l}0.005 \% \text { equivalent to a } \\
\text { value of EUR } 5\end{array}$ & $\begin{array}{l}0.01 \% \text { equivalent to a } \\
\text { value of EUR } 10\end{array}$ & $\begin{array}{l}0.01 \% \text { equivalent to a } \\
\text { value of EUR } 10\end{array}$ \\
\hline Final settlement price & \multicolumn{3}{|c|}{$\begin{array}{l}\text { The final settlement price is established by Eurex on the final settlement day } \\
\text { at 12:30 CET, based on the volume-weighted average price of all trades } \\
\text { during the final minute of trading, provided that more than } 10 \text { trades } \\
\text { occurred during this minute; otherwise the volume-weighted average price } \\
\text { of the last } 10 \text { trades of the day, provided that these are not older than } 30 \\
\text { minutes. If such a price cannot be determined, or does not reasonably reflect } \\
\text { the prevailing market conditions, Eurex will establish the final settlement } \\
\text { price. }\end{array}$} \\
\hline
\end{tabular}

Note: This table presents the interest rate futures contract specifications: fixed-income futures. 
Table 2

Quality option price

\begin{tabular}{|c|c|c|c|c|c|}
\hline & Period & Average & $\begin{array}{l}\text { Standard } \\
\text { deviation }\end{array}$ & Maximum & Minimum \\
\hline \multirow{5}{*}{$\begin{array}{l}\text { Euro-Schatz } \\
\text { Futures }\end{array}$} & Whole sample & 2.776 & 469 & 3.366 & 1.673 \\
\hline & Positive 1-month & & & & \\
\hline & $\begin{array}{l}\text { Euribor rate sub- } \\
\text { period }\end{array}$ & 2.150 & 395 & 2.880 & 1.673 \\
\hline & Negative 1-month & & & & \\
\hline & $\begin{array}{l}\text { Euribor rate sub- } \\
\text { period }\end{array}$ & 2.446 & 505 & 3.366 & 1.724 \\
\hline \multirow{5}{*}{$\begin{array}{l}\text { Euro-Bobl } \\
\text { Futures }\end{array}$} & Whole sample & 3.562 & 1.112 & 5.367 & 1.964 \\
\hline & Positive 1-month & & & & \\
\hline & $\begin{array}{l}\text { Euribor rate sub- } \\
\text { period }\end{array}$ & 3.167 & 1.061 & 5.367 & 1.964 \\
\hline & Negative 1-month & & & & \\
\hline & $\begin{array}{l}\text { Euribor rate sub- } \\
\text { period }\end{array}$ & 4.164 & 900 & 5.190 & 2.157 \\
\hline \multirow{5}{*}{$\begin{array}{l}\text { Euro-Bund } \\
\text { Futures }\end{array}$} & Whole sample & 4.901 & 2.640 & 11.868 & 566 \\
\hline & Positive 1-month & & & & \\
\hline & $\begin{array}{l}\text { Euribor rate sub- } \\
\text { period }\end{array}$ & 4.432 & 2.313 & 11.100 & 566 \\
\hline & Negative 1-month & & & & \\
\hline & $\begin{array}{l}\text { Euribor rate sub- } \\
\text { period }\end{array}$ & 5.622 & 2.942 & 11.868 & 1.442 \\
\hline
\end{tabular}

Note: This table presents the quality option price statistics using the Euro-Schatz Future contract, the EuroBobl Future contract and the Euro-Bund Future contract in the period June 2012 to December 2016 using daily data. Values are in euros. The negative one-month Euribor rate sub-period starts from 26 February onwards and the corresponding number of observations is 443 , which accounts for around $40 \%$ of the total observations. 
Table 3

Descriptive statistics

Whole sample

\begin{tabular}{lcccc}
\hline Panel A: Summary Statistics & Average return & Standard deviation & Skewness & Kurtosis \\
\hline Schatz quality option asset & $0.39 \%$ & $1.15 \%$ & 0.44 & 2.07 \\
Bobl quality option asset & $0.28 \%$ & $2.27 \%$ & -0.56 & 10.92 \\
Bund quality option asset & $0.51 \%$ & $4.35 \%$ & 0.69 & 4.11 \\
German government bond index & $0.01 \%$ & $0.26 \%$ & -0.52 & 2.17 \\
DAX & $0.07 \%$ & $1.19 \%$ & -0.23 & 1.90 \\
\hline
\end{tabular}

Positive 1-month Euribor rate sub-period

\begin{tabular}{|c|c|c|c|c|}
\hline Panel A.1: Summary Statistics & Average return & Standard deviation & Skewness & Kurtosis \\
\hline Schatz quality option asset & $0.05 \%$ & $0.97 \%$ & 0.26 & 3.09 \\
\hline Bobl quality option asset & $0.06 \%$ & $2.59 \%$ & -0.52 & 10 \\
\hline Bund quality option asset & $0.03 \%$ & $4.53 \%$ & 0.48 & 3.59 \\
\hline German government bond index & $0.02 \%$ & $0.21 \%$ & -0.24 & 0.64 \\
\hline DAX & $0.08 \%$ & $1.02 \%$ & -0.03 & 1.41 \\
\hline
\end{tabular}

Negative 1-month Euribor rate sub-period

\begin{tabular}{lcccc}
\hline Panel A.2: Summary Statistics & Average return & Standard deviation & Skewness & Kurtosis \\
\hline Schatz quality option asset & $0.90 \%$ & $1.22 \%$ & 0.24 & 1.89 \\
Bobl quality option asset & $0.62 \%$ & $1.60 \%$ & 0.33 & 2.21 \\
Bund quality option asset & $1.24 \%$ & $3.94 \%$ & 1.44 & 5.40 \\
German government bond index & $0.00 \%$ & $0.31 \%$ & -0.52 & 1.63 \\
DAX & $0.03 \%$ & $1.42 \%$ & -0.30 & 1.41 \\
\hline
\end{tabular}


Note: These tables present the main statistics of the following asset returns: the quality option assets involving the Euro-Schatz Future contract, the Euro-Bobl Future contract and the Euro-Bund Future contract, the DAX and German government bond index in the period June 2012 to December 2016 using daily data. The negative one-month Euribor rate sub-period starts from 26 February onwards and the corresponding number of observations is 443 , which accounts for around $40 \%$ of the total observations. 


\begin{tabular}{|c|c|c|c|c|c|}
\hline \multirow[b]{2}{*}{$\begin{array}{l}\text { Panel B: Correlation } \\
\text { matrix }\end{array}$} & \multicolumn{5}{|c|}{ Whole sample } \\
\hline & $\begin{array}{l}\text { Schatz quality } \\
\text { option asset }\end{array}$ & $\begin{array}{l}\text { Bobl quality } \\
\text { option asset }\end{array}$ & $\begin{array}{l}\text { Bund quality } \\
\text { option asset }\end{array}$ & $\begin{array}{c}\text { German } \\
\text { government } \\
\text { bond index }\end{array}$ & Eurostoxx 50 \\
\hline $\begin{array}{l}\text { Schatz quality } \\
\text { option asset }\end{array}$ & 1 & & & & \\
\hline $\begin{array}{l}\text { Bobl quality option } \\
\text { asset }\end{array}$ & 0.53 & 1 & & & \\
\hline $\begin{array}{l}\text { Bund quality option } \\
\text { asset }\end{array}$ & 0.39 & 0.66 & 1 & & \\
\hline $\begin{array}{l}\text { German } \\
\text { government bond } \\
\text { index }\end{array}$ & -0.30 & -0.33 & -0.31 & 1 & \\
\hline DAX & 0.06 & 0.04 & 0.04 & -0.27 & 1 \\
\hline
\end{tabular}

Positive 1-month Euribor rate sub-period

\begin{tabular}{|c|c|c|c|c|c|}
\hline $\begin{array}{l}\text { Panel B.1: } \\
\text { Correlation matrix }\end{array}$ & $\begin{array}{c}\text { Schatz quality } \\
\text { option asset }\end{array}$ & $\begin{array}{l}\text { Bobl quality } \\
\text { option asset }\end{array}$ & $\begin{array}{l}\text { Bund quality } \\
\text { option asset }\end{array}$ & $\begin{array}{c}\text { German } \\
\text { government } \\
\text { bond index }\end{array}$ & Eurostoxx 50 \\
\hline $\begin{array}{l}\text { Schatz quality } \\
\text { option asset }\end{array}$ & 1 & & & & \\
\hline $\begin{array}{l}\text { Bobl quality option } \\
\text { asset }\end{array}$ & 0.56 & 1 & & & \\
\hline $\begin{array}{l}\text { Bund quality option } \\
\text { asset }\end{array}$ & 0.37 & 0.67 & 1 & & \\
\hline $\begin{array}{l}\text { German } \\
\text { government bond } \\
\text { index }\end{array}$ & -0.37 & -0.17 & -0.18 & 1 & \\
\hline DAX & 0.09 & 0.00 & 0.04 & -0.31 & 1 \\
\hline
\end{tabular}


Negative 1-month Euribor rate sub-period

\begin{tabular}{|c|c|c|c|c|c|}
\hline $\begin{array}{l}\text { Panel B.2 : } \\
\text { Correlation matrix }\end{array}$ & $\begin{array}{l}\text { Schatz quality } \\
\text { option asset }\end{array}$ & $\begin{array}{l}\text { Bobl quality } \\
\text { option asset }\end{array}$ & $\begin{array}{l}\text { Bund quality } \\
\text { option asset }\end{array}$ & $\begin{array}{c}\text { German } \\
\text { government } \\
\text { bond index }\end{array}$ & Eurostoxx 50 \\
\hline $\begin{array}{l}\text { Schatz quality } \\
\text { option asset }\end{array}$ & 1 & & & & \\
\hline $\begin{array}{l}\text { Bobl quality option } \\
\text { asset }\end{array}$ & 0.56 & 1 & & & \\
\hline $\begin{array}{l}\text { Bund quality option } \\
\text { asset }\end{array}$ & 0.37 & 0.64 & 1 & & \\
\hline $\begin{array}{l}\text { German } \\
\text { government bond } \\
\text { index }\end{array}$ & -0.27 & -0.66 & -0.48 & 1 & \\
\hline DAX & 0.07 & 0.14 & 0.06 & -0.25 & 1 \\
\hline
\end{tabular}

Note: These tables present the correlation matrices of the returns of the following assets: the quality option assets involving the Euro-Schatz Future contract, the Euro-Bobl Future contract and the Euro-Bund Future contract, the DAX and a German government bond index in the period June 2012 to December 2016 using daily data. The negative one-month Euribor rate sub-period starts from 26 February onwards and the corresponding number of observations is 443 , which accounts for around $40 \%$ of the total observations. 
Table 4

GMM mean-variance spanning test

\section{Whole sample}

Test of overidentifying restriction

\begin{tabular}{lcc}
\hline & $\chi_{n}^{2}$ & $p$-value \\
\hline $\begin{array}{l}\text { Schatz quality } \\
\text { option (n=2) }\end{array}$ & 207.95 & 0.00 \\
$\begin{array}{l}\text { Bobl quality } \\
\text { option ( } n=2)\end{array}$ & 137.59 & 0.00 \\
$\begin{array}{l}\text { Bund quality } \\
\text { option (n=2) }\end{array}$ & 0.00 \\
All in (n=6) & 45.44 & \\
\hline
\end{tabular}

Positive 1-month Euribor rate sub-period

Test of overidentifying restriction

\begin{tabular}{lcc}
\hline & $\chi_{n}^{2}$ & $p$-value \\
\hline $\begin{array}{l}\text { Schatz quality } \\
\text { option (n=2) }\end{array}$ & 127.64 & 0.00 \\
$\begin{array}{l}\text { Bobl quality } \\
\text { option ( } n=2)\end{array}$ & 70.54 & 0.00 \\
$\begin{array}{l}\text { Bund quality } \\
\text { option (n=2) }\end{array}$ & 15.23 & 0.00 \\
All in (n=6) & 128.12 & 0.00 \\
\hline
\end{tabular}




\section{Negative1-month Euribor rate sub-period}

Test of overidentifying restriction

\begin{tabular}{lcc}
\hline & $\chi_{n}^{2}$ & $p$-value \\
\hline $\begin{array}{l}\text { Schatz quality } \\
\text { option ( } \mathrm{n}=2)\end{array}$ & 101.56 & 0.00 \\
$\begin{array}{l}\text { Bobl quality } \\
\text { option ( } \mathrm{n}=2)\end{array}$ & 73.01 & 0.00 \\
$\begin{array}{l}\text { Bund quality } \\
\text { option }(\mathrm{n}=2)\end{array}$ & 18.95 & 0.00 \\
All in $(\mathrm{n}=6)$ & 103.36 & 0.00 \\
\hline
\end{tabular}

Note: These tables present the results of MacKinlay and Richardson's (1991) GMM approach to testing mean-variance efficiency. We carry out these statistical tests considering the whole sample and also two subsamples that are characterized by the presence of a positive (negative) one-month Euribor rate along the first (second) subsample. We perform the tests considering the following assets: the quality option assets involving the Euro-Schatz Future contract, the Euro-Bobl Future contract and the Euro-Bund Future contract, the DAX and a German government bond index in the period June 2012 to December 2016 using daily data. We compute the test for each quality option asset separately ( $N=1$ and $K=2)$. Hence, we answer the question of which quality option assets expand the mean-variance frontier based on the DAX, the German government bond index and the one-month Euribor rate considered as the risk-free rate. Finally, we conduct the analysis considering all the quality option assets $(N=3$ and $K=2)$. 
Table 5

Optimal portfolio weights

Whole sample

\begin{tabular}{|c|c|c|}
\hline & Traditional assets & $\begin{array}{c}\text { Traditional assets and quality } \\
\text { option assets }\end{array}$ \\
\hline Schatz quality option asset & & 0.32 \\
\hline Bobl quality option asset & & -0.03 \\
\hline Bund quality option asset & & 0.01 \\
\hline $\begin{array}{l}\text { German government bond } \\
\text { index }\end{array}$ & 0.81 & 0.64 \\
\hline DAX & 0.19 & 0.06 \\
\hline
\end{tabular}

Positive 1-month Euribor rate sub-period

\begin{tabular}{|c|c|c|}
\hline & Traditional assets & $\begin{array}{c}\text { Traditional assets and quality } \\
\text { option assets }\end{array}$ \\
\hline Schatz quality option asset & & 0.11 \\
\hline Bobl quality option asset & & 0.00 \\
\hline Bund quality option asset & & 0.00 \\
\hline $\begin{array}{l}\text { German government bond } \\
\text { index }\end{array}$ & 0.83 & 0.77 \\
\hline DAX & 0.17 & 0.12 \\
\hline
\end{tabular}


Negative 1-month Euribor rate sub-period

\begin{tabular}{|c|c|c|}
\hline & Traditional assets & $\begin{array}{c}\text { Traditional assets and quality } \\
\text { option assets }\end{array}$ \\
\hline Schatz quality option asset & & 0.31 \\
\hline Bobl quality option asset & & 0.04 \\
\hline Bund quality option asset & & 0.02 \\
\hline $\begin{array}{l}\text { German government bond } \\
\text { index }\end{array}$ & 0.68 & 0.61 \\
\hline DAX & 0.31 & 0.02 \\
\hline
\end{tabular}

Note: The table presents the optimal tangency portfolio weights for the traditional portfolio consisting of the DAX and Germany government bond index and for the expanded portfolio, which also includes the quality option assets. The data cover the period from June 2012 to December 2016 using daily data. 
Table 6

Out-of-sample portfolio weights

Traditional assets and quality option

Traditional assets assets

\begin{tabular}{|c|c|c|c|c|c|c|c|c|}
\hline & Average & $\begin{array}{l}\text { Standard } \\
\text { deviation }\end{array}$ & Max & Min & Average & $\begin{array}{l}\text { Standard } \\
\text { deviation }\end{array}$ & Max & Min \\
\hline Schatz quality option asset & & & & & 0.21 & 0.06 & 0.27 & 0.10 \\
\hline Bobl quality option asset & & & & & 0.00 & 0.01 & 0.05 & -0.02 \\
\hline Bund quality option asset & & & & & 0.01 & 0.01 & 0.01 & -0.01 \\
\hline $\begin{array}{l}\text { German government bond } \\
\text { index }\end{array}$ & 0.87 & 0.02 & 0.92 & 0.79 & 0.72 & 0.04 & 0.79 & 0.66 \\
\hline DAX & 0.13 & 0.02 & 0.21 & 0.08 & 0.06 & 0.03 & 0.13 & 0.02 \\
\hline
\end{tabular}

Note: The table presents the out-of-sample optimal tangency portfolio weights for the traditional portfolio consisting of the DAX and Germany government bond index and for the expanded portfolio, which also includes the quality option assets. The data cover the period from 25 February 2015 to December 2016 using daily data. 


\section{Table 7}

Investment performance of the optimized strategies. Out-of-sample results.

\begin{tabular}{lcccc}
\cline { 2 - 4 } & $\begin{array}{l}\text { Mean } \\
\text { return }\end{array}$ & Sharpe ratio & Portfolio turnover & Return loss \\
\hline Traditional assets & 0.043 & 1.41 & 0.239 & 0.0175 \\
\hline $\begin{array}{l}\text { Traditional assets and } \\
\text { quality option assets }\end{array}$ & 0.074 & 1.99 & 0.276 & \\
\hline
\end{tabular}

Note: The table presents the out-of-sample optimal portfolio economic performance measures for the traditional portfolio consisting of stocks and the German government bond index and for the expanded portfolio, which also includes the quality option assets. The data cover the period from 25 February 2015 to December 2016 using daily data. 


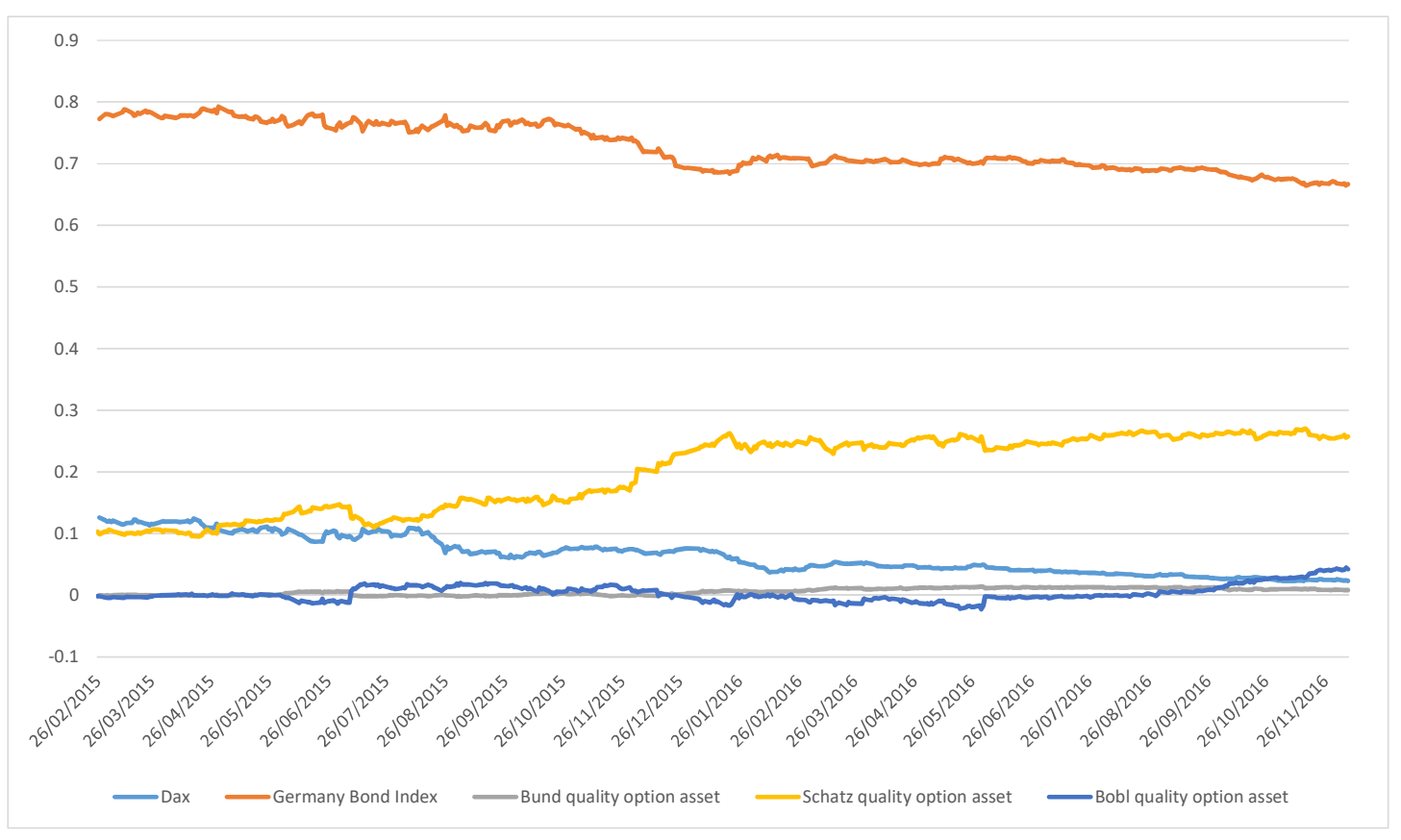

Fig. 1. Evolution of optimal out-of-sample optimal tangency portfolio weights.

This figure plots the out-of-sample optimal tangency portfolio weights for the portfolio that consists of the DAX, German government bond index and the quality option assets. The data cover the period from 25 February 2015 to December 2016 using daily data. 


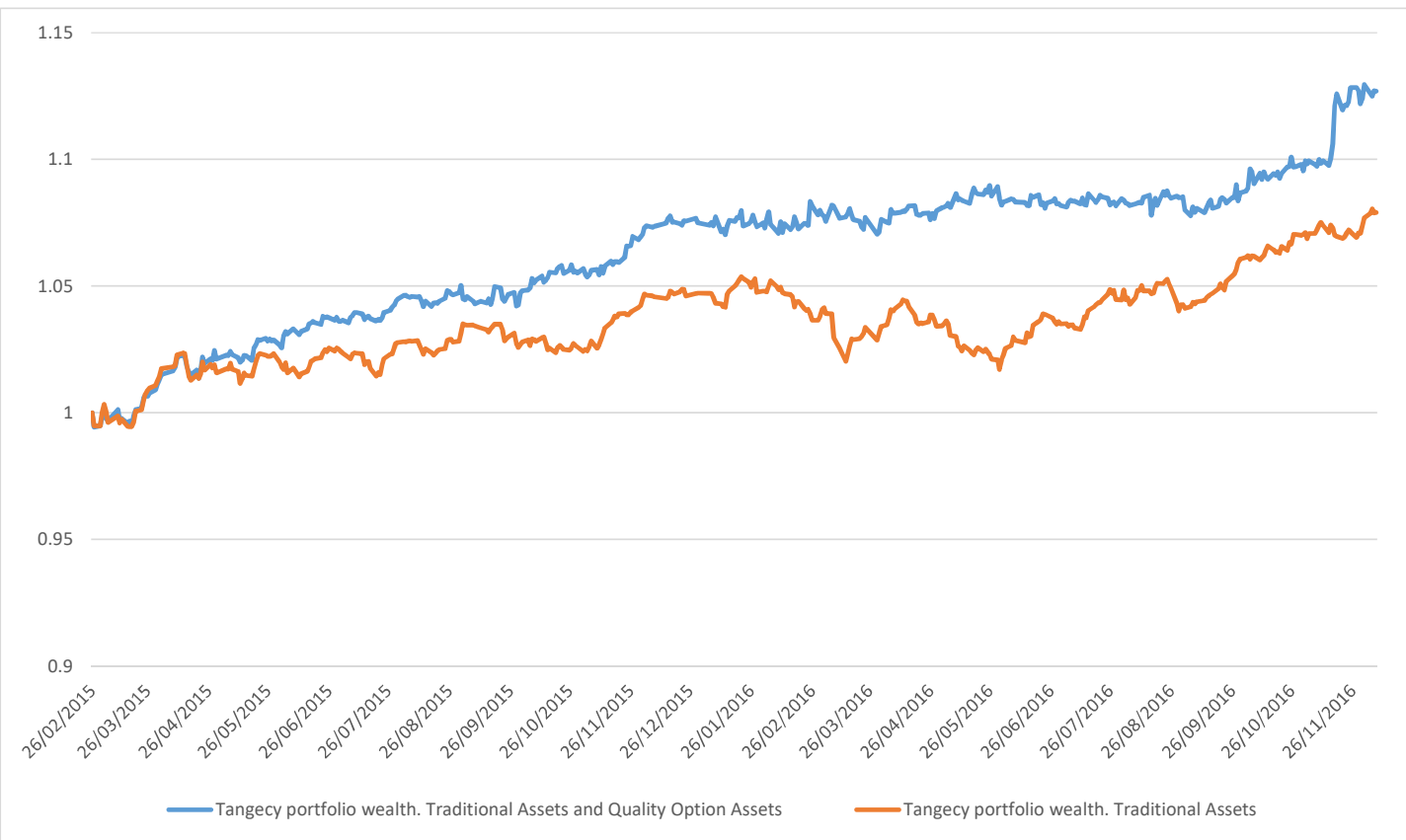

Fig. 2. Evolution of financial wealth. Out-of-sample analysis.

This figure plots the out-of-sample optimal wealth obtained by investing in the optimal tangency portfolio for the traditional portfolio consisting of stocks and bonds and for the expanded portfolio, which also includes the quality option assets. The data cover the period from 25 February 2015 to December 2016 using daily data. 